\title{
Challenges of tackling non COVID-19 emergencies during the unprecedent pandemic
}

\author{
David Mukunya, James K Tumwine
}

Department of Paediatrics and Child Health, Makerere University College of Health Sciences, Kampala, Uganda DOI: https://dx.doi.org/10.4314/ahs.v20i1.2

Cite as: Mukunya D, Tumwine JK. Challenges of tackling non COVID-19 emergencies during the unprecedent pandemic. Afri Health Sci. 2020;20(1):V-VI. https:// dx.doi.org/10.4314/abs.v20i1.2

The Coronavirus disease, which was first reported in December 2019 in China ${ }^{1}$, has now set foot in sub-Saharan Africa with at least 47 countries affected. As of March 31st 2020, over 800,000 confirmed cases of COVID-19 and 40,000 related deaths have been reported worldwide. Of this global burden, 3500 cases and 78 deaths occurred in sub-Saharan Africa. Consequently, in a rare display of prudency and pro-activeness, African governments have instituted widespread lock downs to avert crises such as have been seen in China, Italy and Spain.

To illustrate this, we will describe some of the measures taken by the government of Uganda(GOU). On 30th March 2020, with 33 active COVID-19 cases and, fortunately, no deaths, the government announced a series of measures to try and contain the spread of the disease. In addition to a previous ban on all forms of public transport (including the ubiquitous motorcycles or boda-bodas as they are locally known), GOU banned private vehicles from moving on the streets. In addition, a daily curfew was declared from 19:00 hours until 06.30 hours for 14 days.

The measures taken to control the spread of COVID-19 were prudent and a genuine effort trying to avert catastrophes that have been observed in China, Italy and Spain, where there has been untold suffering and death of patients and health care workers.

Reactions of sections of the community were widespread with some expressing concern about unintended negative consequences of these measures on the health system, particularly on maternal and child health care service utilization. Some wondered how women in labor during the curfew period would reach the nearest health facility. They also wondered how health workers would get to the health facilities. The GOU was very much on top of the situation and in a subsequent broadcast the President clarified many of the issues and asked the National task to elaborate and operationalize the details. Clearly the COVID-19 is very frightening and measures to systematically control it are very welcome, especially since this is a new virus that appears to be a moving target. Our hope is that the health of mothers and children will not bear the brunt of the unintended consequences of the plausible measures being implemented. Fortunately some of the task force members had experience controlling the Ebola crisis in West Africa. Following that crisis, there was an unprecedent decline in maternal and child health indicators, and these needed targeted interventions to return to the pre-epidemic levels ${ }^{2,3}$. For example, reporting of health facilities declined by $50 \%$, caesarean sections declined by $50 \%{ }^{4}$, and non-Ebola mortality increased substantially $^{5}$.

As we implement interventions for controlling COVID-19, we must not lose sight of other conditions that the country has been grappling with, and which can potentially increase morbidity and mortality. Apart from challenges with maternal and newborn health, this outbreak will impact on the care of patients with infections such as pneumonia, diarrhea, malaria, HIV/AIDS and tuberculosis.

In addition, the care for patients with non communicable diseases such as cancer, cardiovascular diseases, hypertension, sickle cell disease, diabetes mellitus and others 5 might be compromised. The stigma surrounding COVID $-19^{6}$ will further discourage health seeking. In addition, the socio-economic impact of COVID-19 will inevitably result in a large burden of malnutrition and mental health issues.

This outbreak has come at the wrong time when the country had made a lot of public health gains in the past two decades. Thus, it is very important to keep an eye on these issues as we tackle this pressing COVID-19 epidemic. But not all will be lost. The COVID-19 epwork is properly cited. 
idemic could potentially result in an overall reduction in diarrhea and pneumonia related mortality; however, these gains may be eroded by the concerns we raise above. To stimulate discussion, and with no claim of being exhaustive, we highlight a few potential points that the Ministry could pick up going forward.

\section{Way forward}

1) Undertake horizontal instead of vertical approaches to tackling COVID-19

2) Give clear guidelines on continuity of core health care functions at health facilities

3) Have a dedicated non-COVID related mortality data monitoring team e.g. monitoring maternal mortality during this COVID era

4) Work out clear modalities for giving permission to and means to transport emergencies from communities at all times

5) Sustain the delivery of essential medical supplies to patients in communities, through community health workers

6) Utilize community health workers in the fight against COVID-19

\section{References}

1. Cunningham AC, Goh HP, Koh D. Treatment of COVID-19: old tricks for new challenges. Crit Care. 2020;24(1):91.

2. Delamou A, Hammonds RM, Caluwaerts S, Utz B, Delvaux T. Ebola in Africa: beyond epidemics, reproductive health in crisis. Lancet. 2014;384(9960):2105.

3. Delamou A, Ayadi AME, Sidibe S, et al. Effect of Ebola virus disease on maternal and child health services in Guinea: a retrospective observational cohort study. Lancet Glob Health. 2017;5(4):e448-e457.

4. Shannon FQ, 2nd, Horace-Kwemi E, Najjemba R, et al. Effects of the 2014 Ebola outbreak on antenatal care and delivery outcomes in Liberia: a nationwide analysis. Public Health Action. 2017;7(Suppl 1):S88-s93.

5. Brolin Ribacke KJ, Saulnier DD, Eriksson A, von Schreeb J. Effects of the West Africa Ebola Virus Disease on Health-Care Utilization - A Systematic Review. Front Public Health. 2016;4:222.

6. Mugerwa F. Coronavirus: Patients flee from Hoima Hospital Kampala: Daily Monitor; 2020 cited 2020 31st March. Available from: https://http://www.monitor. co.ug/News/National/Coronavirus-Patients-flee-Hoima-Hospital/688334-5507978-14o4yy4/index.html. 